Vie et mort des revues en période coloniale et postcoloniale

\title{
Avant/inter-textes, inter/avant-textes : génétique et intertextualité
}

Programme du séminaire

\section{Kora Véron}

\section{OpenEdition}

\section{Journals}

Édition électronique

URL : http://journals.openedition.org/coma/898

DOI : $10.4000 /$ coma.898

ISSN : 2275-1742

Éditeur

Institut des textes \& manuscrits modernes (ITEM)

\section{Référence électronique}

Kora Véron, «Avant/inter-textes, inter/avant-textes : génétique et intertextualité », Continents

manuscrits [En ligne], 9 | 2017, mis en ligne le 20 septembre 2017, consulté le 21 avril 2019. URL :

http://journals.openedition.org/coma/898 ; DOI : 10.4000/coma.898

Ce document a été généré automatiquement le 21 avril 2019.

\section{c)}

Continents manuscrits - Génétique des textes littéraires - Afrique, Caraîbe, dispora est mis à disposition selon les termes de la licence Creative Commons Attribution - Pas d'Utilisation Commerciale - Pas de Modification 4.0 International. 


\section{Avant/inter-textes, inter/avant- textes : génétique et intertextualité}

Programme du séminaire

Kora Véron

Un vendredi par mois, $14 \mathrm{~h} 30$ - 17 h 30, École normale supérieure, 45, rue d'Ulm, 75005 Paris

Ce séminaire est ouvert à tous dans la mesure des places disponibles

Responsable: Kora Véron (koraveron@orange.fr)

\section{3 octobre 2017 - salle Celan}

1 Ouverture du séminaire

- Pierre-Marc de Biasi (ITEM) : «Introduction théorique : écriture littéraire et exogenèse » Actualité

Claire Riffard (ITEM) : Le dernier voyage d'étude de l'équipe à Madagascar.

\section{0 novembre 2017 - salle Celan}

2 Séance commune avec le séminaire Afriques transversales de l'École normale supérieure

- Pierre Leroux (Paris III) : « Réédition et collage, le travail de l'œuvre poétique chez JeanJacques Dabla»

- Ninon Chavoz (ENS) et Elara Bertho (CNRS): «Pratiques des écrivains reçus dans le séminaire Afriques transversales depuis deux ans »

Actualité

Pierre Leroux : Présentation des deux derniers numéros de la revue Po\&sie consacrés aux poètes africains contemporains.

\section{5 décembre 2017 - salle des Actes}

3 -Hervé Sanson (ITEM) : «Le "garde-manger" d'Albert Memmi : d'un usage singulier des avant-textes. Genèses(s) de L'Homme dominé "

-Céline Gahungu (Paris-Sorbonne) : « Yambo Ouologuem/Nelly Brigitta : masques, jeux et 
miroitements littéraires »

Actualité

Albert Memmi, Tunisie an I, texte édité et annoté par Guy Dugas. CNRS Éditions, 2017.

Penser à vif. De la colonisation à la laïcité (1941-2002), textes réunis et présentés par H. Sanson. Non lieu éditions, 2017.

\section{6 janvier 2018 - salle $235 \mathrm{~A}$}

- Kathleen Gyssels (Université d'Anvers): «Interlignes de Léon Gontran Damas: résonances poétiques »

\section{6 février 2018 - salle Celan}

- Yves Chemla (ITEM) : « Voyage dans le Nord d'Hayti ou Révélations des lieux et des monuments historiques, d'Hérard Dumesle (1824), un hypotexte fondateur »

- Jérôme Poinsot(Université de Cergy-Pontoise): «Écrire avec les autres: dialogue intertextuel dans le roman Hadriana dans tous mes rêves de René Depestre »

\section{6 mars 2018 - salle Celan}

6 - Guy Dugas (Montpelier III) : «L'Affaire Isabelle Eberhardt par les textes : Barrucand, Stéphan et Doyon plagiaires ou serviteurs de l'œuvre?»

- Ninon Chavoz (ENS) : «Une fête des masques: intertextualités suspectes chez Sami Tchak et Alain Mabanckou »

\section{3 avril 2018 - Journée d'étude Aimé Césaire}

7 Matin - salle Dussane

Table ronde autour de la mise en œuvre de l'édition génétique numérique de Cahier d'un retour au pays natal

- Aurèle Crasson (ITEM)

- Jean-Sébastien Macke (ITEM)

- Jeremy Pedrazzi (ITEM)

- Kora Véron (ITEM)

Après-midi - salle Celan

- Dimitri Bechacq (Université des Antilles) : «Interroger les usages de la "race" à partir des sources écrites. Sur les traces de Suzanne et d'Aimé Césaire à Port-au-Prince en 1944 » - Anne-Sophie Bories (Université de Bâle) : «Les rythmes du Cahier au crible de l'analyse quantitative »

- Alex Gil (Columbia) : «Et les chiens se taisaient, édition spéculative et essai génétique »

- Claire Shi (Paris-Sorbonne/Université de Nankin) : «Le héros césairien : entre la Grèce et les Antilles »

- Kora Véron (ITEM) : « Apollinaire - Césaire - Celan : « N’ayez-point pitié de moi », signes de connivence »

\section{8 mai 2018 - salle Celan}

8 Séminaire croisé autour des bibliothèques d'écrivains

- «Manuscrits italiens », Monica Zanardo (ITEM) : " "Car sans doute inventer c'est sans 
exception se souvenir". Parcours génétiques dans la bibliothèque d'Elsa Morante » - «Manuscrits francophones", Jean-Pierre Orban (ITEM) : "Écrire dans les livres des autres : la bibliothèque d'André Schwarz-Bart »

\section{9 juin 2018 - BNF - salle Celan}

9 Matin - BNF (Richelieu)

Séance Mohammed Dib avec la Bibliothèque nationale

- Isabelle Mette (BNF): Présentation des archives Dib conservées à la Bibliothèque nationale et des travaux du groupe Dib.

- Abdellah Romli (Université de Kénitra) : «Talilo est mort ou le souvenir d'une œuvre écrite »

Après-midi - salle Celan

- Charles Scheel (Université des Antilles): «Le contexte culturel martiniquais de 1939-1945 et les premières nouvelles de Joseph Zobel »

\section{AUTEUR}

\section{KORA VÉRON}

Chercheur associé, équipe Manuscrits francophones, ITEM (CNRS-ENS) 